\title{
Population dynamics and evaluation of the partial selective treatment of crossbreed steers naturally infested with Rhipicephalus (Boophilus) microplus in a herd from the state of Minas Gerais in Brazil
}

\author{
Lucas Vinicius Costa Gomes ${ }^{\mathrm{a}}$, Welber Daniel Zanetti Lopes ${ }^{\mathrm{a}, \mathrm{b}, *}$, \\ Weslen Fabricio Pires Teixeira ${ }^{a}$, Willian Giquelin Maciel ${ }^{a}$, Breno Cayeiro Cruz ${ }^{\mathrm{a}}$, \\ Gustavo Felippelli ${ }^{a}$, Carolina Buzzulini ${ }^{a}$, Vando Edésio Soares ${ }^{\mathrm{a}, \mathrm{c}}$, \\ Daniel Pacheco de Melo a , Murilo Abud Bichuette ${ }^{a}$, Geraldo Gonçalves Junior ${ }^{a}$, \\ Alvimar José da Costa ${ }^{a}$
}

\footnotetext{
${ }^{a}$ Faculdade de Ciências Agrárias e Veterinárias, UNESP/CPPAR, Access route Prof. Paulo Donatto Castellane, CEP: 14884-900 Jaboticabal, São Paulo, Brazil

b Instituto de Patologia Tropical e Saúde Pública, Universidade Federal de Goiás, Goiânia, GO 74605050, Brazil

${ }^{\mathrm{c}}$ UNICASTELO-Universidade Camilo Castelo Branco, Brazil
}

\section{A R T I C L E I N F O}

\section{Article history:}

Received 25 September 2015

Received in revised form 22 February 2016

Accepted 26 February 2016

\section{Keywords:}

Generations

Partial treatment

Resistance

Southern cattle tick

\begin{abstract}
A B S T R A C T
The present study aimed to evaluate the population dynamics of Rhipicephalus (Boophilus) microplus over a period of 13 months on a rural property located in the state of Minas Gerais in southeastern Brazil. Animals were treated for ticks indoors by whole body spraying when $R$. (B.) microplus had an average count equal or more than 30 ticks. The study also evaluated the possibility of a partial selective treatment for bovines to control $R$. (B.) microplus in which only a percentage of the population would be treated (specifically those bovines with tick counts of $\geq 20$. Moreover, we examined the percentage of the population of $R$. (B.) microplus present on experimental bovines that did not come into contact with the chemical compounds used in the partial selective treatment. We concluded that in this particular region of Brazil, the crossbreed steers support up to five $R$. (B.) microplus generations per year and that the number of generations was primarily affected by the pluviometric precipitation. We sprayed the bovines with chemicals seven times during the course of the study. The results of the partial selective treatment method revealed that during the rainy and the dry periods, $42.1 \%$ to $60.0 \%$ and $61.9 \%$ to $79.2 \%$ of the animals, respectively, fulfilled the criteria to receive a chemical treatment to reduce the number of cattle ticks. In consideration of the need to slow the development of tick resistance with the chemical compounds used in the spraying treatment, the results showed that the percentage of animals that did not require treatment is not relevant. This was evidenced by the result that bovines that presented tick counts of $\geq 20$ during the dry and rainy periods represented $91.5 \%$ and $90.6 \%$ of the total recorded $R$. (B.) microplus populations, respectively. Only $8.7 \%$ of the tick population remained free from exposure to acaricides during the 13 months of the study, which is an important point when considering the adoption of the partial selective treatment method. Future studies with larger herds must be conducted on these topics; however, our results suggest that the partial selective treatment method most likely will not slow the development of resistance in this $R$. (B.) microplus population against the chemical compound used in this study.
\end{abstract}

() 2016 Elsevier B.V. All rights reserved.

\footnotetext{
* Corresponding author at: Instituto de Patologia Tropical e Saúde Pública, Universidade Federal de Goiás, Goiânia, GO 74605050, Brazil.

E-mail addresses: wdzlopes@hotmail.com, wdzlopes@fcav.unesp.br (W.D.Z. Lopes).
}

\section{Introduction}

The southern cattle tick, Rhipicephalus (Boophilus) microplus, is considered as one of the principle causes of the loss of productivity in the cattle industry throughout the world (Lopes et al., 2013, 2014; Gomes et al., 2015). The control of this ectoparasite is based primarily on the use of chemical acaricides (Cruz et al. 2015). Unfortunately, reports of tick resistance to several active 
components in chemical acaricides are increasing (Corrêa et al., 2015). A recent strategy developed for controlling the spread of $R$. (B.) microplus is the partial selective treatment of animals based on infestation level, the objective of which is to retard the development of resistance of the tick to the acaricides. Specifically, only bovines with an elevated number of ticks would receive chemical spraying; thus, a significant portion of the tick population would not be exposed to the formulation/molecule (i.e., those ticks present on the untreated animals). To date, few published studies have examined the effectiveness of this method (Paim et al., 2011; Molento et al., 2013; Nava et al., 2015).

The present study evaluated the population dynamics of $R$. (B.) microplus in naturally infested crossbreed steers (1/4 Bos indicus and 3/4 Bos taurus, non-castrated males) within an extensive grazing area (dominated by the grass Brachiaria decumbens) in the state of Minas Gerais in southeastern Brazil over the course of 13 months. This work also analyzed the viability of a partial selective treatment of bovines to control $R$. (B.) microplus, which considered the percentage of animals that should be treated within the herd based on tick counts and tick size (between 4.5 and $8.0 \mathrm{~mm}$ ). Moreover, the percentage of the $R$. (B.) microplus population present in untreated animals that would have no contact with the chemical products if partial selective treatments were adopted was determined.

\section{Material and methods}

\subsection{Study location, bovines, tick counts and chemical treatments}

The experiment was conducted between October 2013 and October 2014 at the Bela Vista Farm located in the municipality of Formiga in the state of Minas Gerais in southeastern Brazil.

We started with an initial herd of nearly 50 bovines (1/4 B. indicus and $3 / 4$ B. taurus, non-castrated males) from which 24 , between 9 and 10 months were randomly selected. The 24 bovines were distributed evenly into two groups, using a randomized complete block design. The formation of the blocks was based on the arithmetic means of the number of female ticks (measuring $4.5-8.0 \mathrm{~mm}$ ) on bovines that were counted over three consecutive days, as recommended by Wharton and Utech (1970).

During the entire period of the trial, both experimental groups were kept in separate paddocks, each of which were filled with $B$. decumbens and had a stocking rate of 1.5 animal units per hectare. Water and mineral supplements were provided "ad libitum", and commercial ration and corn silage were used as feed.

For the evaluation of the $R$. (B.) microplus population dynamics, counts of female ticks on each animal were performed on days 3,7 , $14,21,28$, and subsequently every 14 days until day 364 (Wharton and Utech, 1970). The counts were always conducted at the same time of the day by the same researcher.

Temperature, relative air humidity and rainfall data were retrieved daily from the climatological station (FORMIGA), located approximately 7 kilometers from the experimental site.

The chemical treatments to control $R$. (B.) microplus, were carried out on bovines from each group by whole body spraying using the following application: $15 \%$ Cypermethrin $+25 \%$ Chlorpyriphos $+15 \%$ Piperonyl Butoxide $+1 \%$ Citronellal (Cyperclor Plus ${ }^{\circledR}$ Pulverização-CEVA Saint Animale). The spraying was carried out when a group had an average tick count equal to or more than 30 and an average tick length between 4.5 and $8.0 \mathrm{~mm}$.

\subsection{Evaluation of partial selective treatment of animals to control R. (B.) microplus}

Prior to the spraying, we also analyzed the potential of the partial selective treatment method to control the number of $R$. (B.) microplus on bovines, according the standard previously established by Paim et al. (2011) and Molento et al. (2013), which stated that only animals that presented $R$. (B.) microplus counts of $\geq 20$ should be treated.

However, in light of the ultimate goal of affecting a delay in the development of tick resistance to acaricides, we assert that the percentages obtained from the partial selective treatment method may be more important in terms of the animals that did not meet the criteria to be treated with a chemical compound. For this reason, on the same dates that each group received the chemical treatments, we evaluated the percentage of the $R$. (B.) microplus population present on the animals that were not treated. Thus, these ticks remained free of exposure to the chemical compounds. To this end, the following formulas were used:

Tick population (\%) quantified on animals that would be treated with a chemical formulation when adopting partial selective treatments

$$
=\frac{\mathrm{A}-\mathrm{B}}{\mathrm{A}} \times 100
$$

where $\mathrm{A}=$ Total of $R$. (B.) microplus (between 4.5 and $8.0 \mathrm{~mm}$ ) quantified on animals of both groups on the treatment day, during each season, or throughout the study (13 months). $\mathrm{B}=$ Total of $R$. (B.) microplus (between 4.5 and $8.0 \mathrm{~mm}$ ) quantified on animals with tick counts $<20$ on the treatment day, during each season, or throughout the study (13 months).

Both variables were analyzed in relation to season (dry and wet) and across seasons.

Tick population (\%) quantified on animals that would NOT be treated with a chemical formulation when adopting partial selective treatments

$$
=\frac{\mathrm{A}-\mathrm{B}}{\mathrm{A}} \times 100
$$

where $\mathrm{A}=$ Total of $R$. (B.) microplus (between 4.5 and $8.0 \mathrm{~mm}$ ) quantified on animals of both groups on the treatment day, during each season, or throughout the study (13 months). $\mathrm{B}=$ Total of $R$. (B.) microplus (between 4.5 and $8.0 \mathrm{~mm}$ ) quantified on animals with tick counts $\geq 20$ the on treatment day, during each season, or throughout the study (13 months). Both variables were analyzed in relation to each season (dry and wet) and across seasons (13 months)

\subsection{Data analysis}

The meteorological parameters (temperature, relative air humidity and rainfall) and the $R$. (B.) microplus counts were correlated using the Pearson coefficient. According to Filho and Junior (2009), the range of possible values for the Pearson coefficient is between -1 and 1 . Negative and positive values of the coefficient signify the following: $0.00-0.30$ indicates a low correlation, $0.31-0.69$ indicates a moderate correlation, and values greater than 0.70 indicate a high correlation. All analyses were conducted using STATISTICA data analysis software (Ver. 10; 2011) by StatSoft Inc. (www.statsoft.com).

\section{Results}

There were five peaks in $R$. (B.) microplus infestation observed over the course of the 13 months (Fig. 1). During the rainy period (October to March), we observed three R. (B.) microplus infestation peaks (October, December and March), whereas there were two peaks were observed in April and July during the dry season (April to September) (Fig. 1). Notably, the rainy season in 2014 lasted until April, and it is important to note that there was rainfall during the 


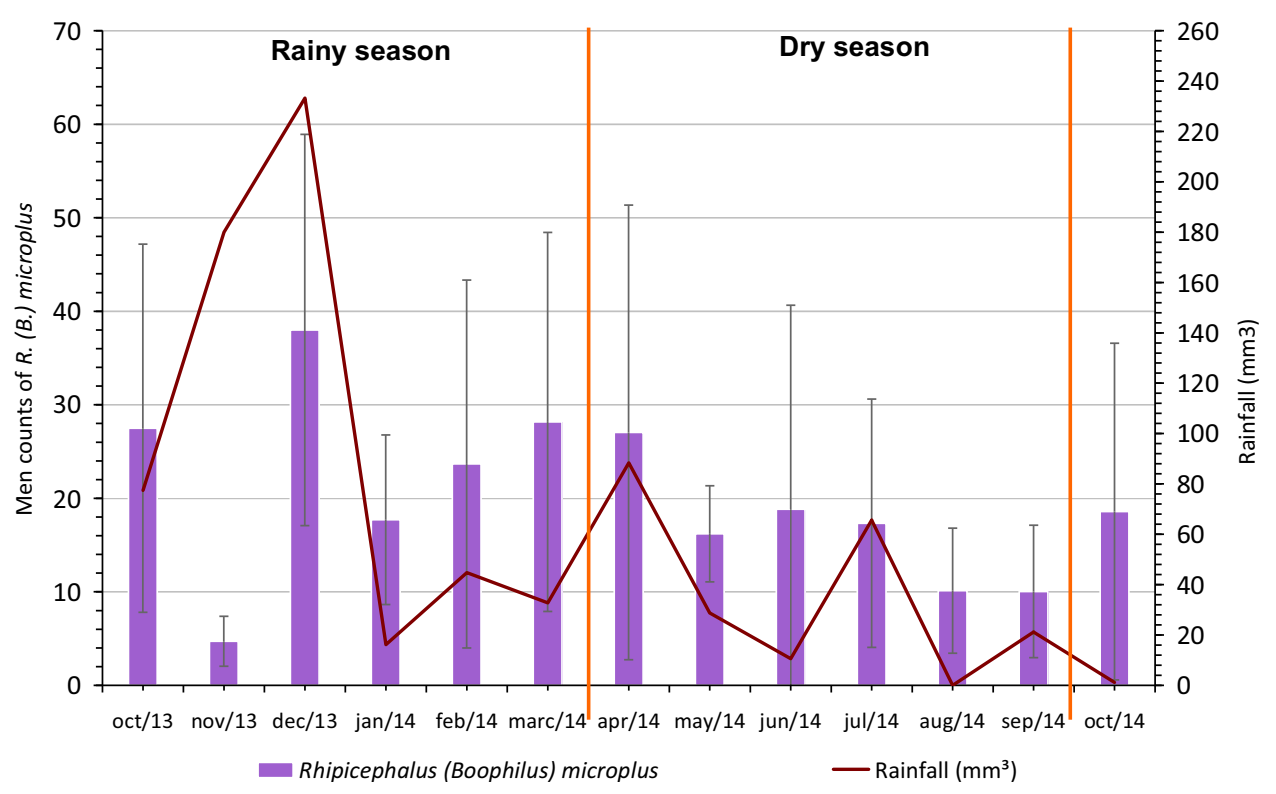

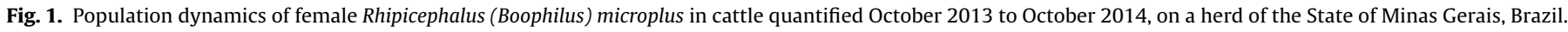

dry season. A positive correlation was observed between the number of ticks on the animals with the amount of pluviometric rainfall $(\mathrm{r}=0.39)$

Between October of 2013 and July of 2014, there were 14 chemical treatments used to control the tick population (seven treatments for each group). The deaths of five animals were registered during this time, of which three were attributed to high levels of $R$. (B.) microplus infestation.

Analysis of the bovines based on the partial selective treatment method conducted on the same dates of the chemical treatments resulted in the following percentages of animals that should receive chemical treatment with the acaricide product: $79.2 \%$ (October 2013), 70.8\% (December 2013), 60.9\% (January 2014), 61.9\% (February 2014), 63.6\% (March 2014), 60.0\% (April 2014), 55.6\% (May 2014), and 42.1\% (July 2014) (Tables 1 and 2). However, the percentages of the total tick population present in these bovines in relation to the dates listed above are as follows, respectively: $88.9 \%, 95.6 \%, 88.2 \%, 93.2 \%, 86.9 \%, 92.9 \%$, 96.1\% and $87.1 \%$. Across the study, an average of $91.3 \%$ of the ticks on the animals would have been exposed to the chemical compound during the study. In other words, if the partial selective treatment method was adopted over the course of the experiment, an average of only $8.7 \%$ of the $R$. (B.) microplus population present on the bovines would have been free from exposure to the chemical product (Table 2).

\section{Discussion}

In the present study, observations over the course of a year of the parasitic phase of $R$. (B.) microplus allowed us to determine that the ectoparasite produced approximately five generations per year. In Colombia, Evans (1978) determined an average of 5.4 and 3.6 generations of $R$. (B.) microplus per year at altitudes of 1000 and 1700 m.a.s.l., respectively.

Regarding the partial selective treatment method, Paim et al. (2011) conducted a study in Santa Catarina in southern Brazil, during three years. The researchers concluded that the partial selective treatments resulted in small economic benefits and was not able to slow the development of $R$. (B.) microplus resistance against an application of $1 \%$ Fipronil. Finally, Nava et al. (2015) applied the partial selective treatment method in northwestern Argentina in which bovines infested by $R$. (B.) microplus were treated with $3.15 \%$
Ivermectin and $2.5 \%$ Fluazuron. They concluded that a yearly application of acaricides to a portion of the herd may not be the most effective methods to significantly control the population of $R$. (B.) microplus in that region.

The selective treatment analysis in this study indicated that the percentages of animals that would not require chemical treatment during the rainy season (61.9-79.2\%) were similar to those obtained by Paim et al. (2011). From the perspective of slowing the development of southern cattle tick resistance to the chemical compounds used in this study, our results show that the percentage of animals that would not receive treatment is largely irrelevant because the majority of the R. (B.) microplus population can be found on a limited number of animals. This hypothesis is confirmed by considering the percentage of animals that would have been treated for tick counts of $\geq 20$ in May (55.6\%) and July (42.1\%) of 2014; these bovines carried $96.1 \%$ and $87.1 \%$, respectively, of the total ticks counted on all animals on these dates. If partial selective treatments were instituted across the 13 months of this study, an average only $8.7 \%$ of the $R$. (B.) microplus population would have remained free from exposure to the chemical compound.

Considering the experimental design, the location of the study, the type of animals under study, and the time period in which the experiment was conducted, we concluded that there are up to five $R$. (B.) microplus generations present per year on the bovines in this region; as previously indicated, the number of generations is related to pluviometric precipitation. Seven chemical applications were used for each group during the course of the study. In regard to the analysis of the partial selective treatments of bovines during the dry and rainy periods, we observed that $42.1-60.0 \%$ and $61.9-79.2 \%$ of all experimental bovines, respectively, would need to receive chemical spraying to counter the southern cattle tick population. Based on the perspective of slowing the development of tick resistance to the tested chemical compounds, our results show that the percentage of animals that would not receive treatment is not relevant. This can be demonstrated by the fact that animals that presented tick counts of $\geq 20$ during the dry and rainy periods carried $91.5 \%$ and $90.6 \%$ of the $R$. (B.) microplus population, respectively. Across the study period (i.e., 13 months), an average of only $8.7 \%$ of the total tick population would remain free from exposure to an acaricide treatment if the partial selective treatments were adopted. Future studies with larger herds must be conducted; 
Table 1

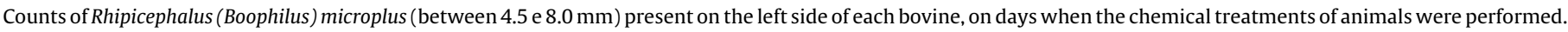

\begin{tabular}{|c|c|c|c|c|c|c|c|c|c|c|}
\hline \multirow[t]{2}{*}{ Animal } & \multirow{2}{*}{ 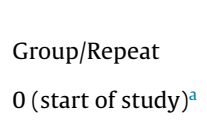 } & \multicolumn{4}{|c|}{$\begin{array}{l}\text { Number of } R \text {. (B.) microplus/Days post initial of study } \\
\text { out } / 13 \quad \text { dez/13 jan/14 }\end{array}$} & \multirow{2}{*}{$\begin{array}{l}\text { fev/14 } \\
154\end{array}$} & \multirow{2}{*}{$\begin{array}{l}\operatorname{mar} / 14 \\
182\end{array}$} & \multirow{2}{*}{$\begin{array}{l}\text { abr/14 } \\
210\end{array}$} & \multirow{2}{*}{$\begin{array}{l}\mathrm{mai} / 14 \\
252\end{array}$} & \multirow[t]{2}{*}{$\mathrm{jul} / 14$} \\
\hline & & 7 & 42 & 70 & 112 & & & & & \\
\hline 1712 & 1 & 5 & 28 & & 17 & 7 & 17 & 10 & NR & 58 \\
\hline 1413 & & 11 & 23 & 99 & 36 & 30 & 58 & 82 & NR & 117 \\
\hline 1812 & & 6 & 18 & 81 & 73 & death & death & death & death & death \\
\hline 1388 & & 7 & 19 & 2 & 2 & 8 & 7 & 4 & NR & 14 \\
\hline 1440 & & 7 & 31 & 122 & 38 & 89 & 52 & 48 & NR & 61 \\
\hline 1656 & & 24 & 21 & 14 & 53 & 132 & 68 & 225 & NR & death \\
\hline 1438 & & 7 & 19 & 14 & 4 & 4 & 32 & 9 & NR & 3 \\
\hline 1546 & & 22 & 28 & 10 & 58 & 9 & 13 & 20 & NR & 1 \\
\hline 1366 & & 28 & 35 & 26 & 12 & 30 & 27 & 25 & NR & 16 \\
\hline 269 & & 24 & 41 & 63 & 11 & 29 & 29 & 31 & NR & 14 \\
\hline 1634 & & 34 & 22 & 95 & 49 & 87 & 45 & 38 & NR & 91 \\
\hline 1368 & & 77 & 93 & 20 & 8 & 4 & 18 & 13 & NR & 8 \\
\hline Mean & & 21.0 & 31.5 & 49.4 & 30.1 & 39.0 & 33.3 & 45.9 & NR & 38.3 \\
\hline 1469 & 2 & 5 & 33 & 121 & 33 & 20 & 14 & NR & 10 & 15 \\
\hline 1355 & & 4 & 22 & 99 & 28 & 68 & 40 & NR & 41 & 38 \\
\hline 53 & & 7 & 25 & 54 & 72 & death & death & death & death & death \\
\hline 1418 & & 6 & 17 & 11 & 58 & 10 & 19 & NR & 1 & 5 \\
\hline 1064 & & 6 & 15 & 18 & 12 & 19 & 19 & NR & 0 & 4 \\
\hline 0293 & & 9 & 29 & 48 & 22 & 35 & 61 & NR & 31 & 53 \\
\hline 1384 & & 11 & 21 & 63 & 33 & 86 & death & death & death & death \\
\hline 1556 & & 24 & 52 & 99 & 18 & 73 & 65 & NR & 55 & 157 \\
\hline 1842 & & 24 & 23 & 188 & 38 & 104 & 56 & NR & 78 & 17 \\
\hline 1572 & & 28 & 35 & 64 & 43 & 53 & 178 & NR & 63 & 81 \\
\hline 0955 & & 33 & 42 & 5 & 1 & 0 & 0 & NR & 0 & 0 \\
\hline 0959 & & 79 & 98 & 319 & death & death & death & death & death & death \\
\hline Mean & & 19.7 & 34.3 & 90.8 & 32.5 & 46.8 & 50.2 & NR & 31.0 & 41.1 \\
\hline
\end{tabular}

$\mathrm{NR}=$ Not realized, group/repeat with mean counts of $R$. (B.) microplus $<30$.

a Treatment was not performed on this day.

Table 2

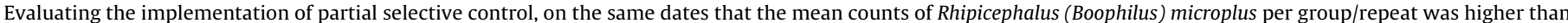
$\geq 30$.

Evaluation of the cattle population with Rhipicephalus (Boophilus) microplus

Variable analyzed Months that were performed the chemical treatments in animals Seasons

Number of animals with counts $>20$ females of $R$. (B.) microplus (between 4.5 to $8.0 \mathrm{~mm}$ ), on day zero of the study

$\overline{\text { out/13 }}$ dez/13 jan/14 fev/14 $\operatorname{mar} / 14$ abr/14 mai/14 jul/14 $\overline{\text { rain drought }}$

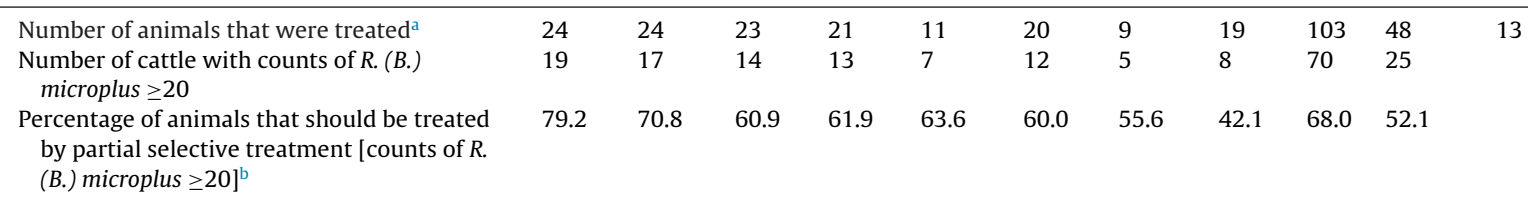

Evaluation of Rhipicephalus (Boophilus) microplus population (between 4.5 to $8.0 \mathrm{~mm}$ ), quantified in cattle

\begin{tabular}{|c|c|c|c|c|c|c|c|c|c|c|c|}
\hline \multirow[t]{2}{*}{ Variable analyzed } & \multicolumn{8}{|c|}{ Months that were performed the chemical treatments in animals } & \multicolumn{2}{|c|}{ Seasons } & \multirow[t]{2}{*}{ Mean (\%) } \\
\hline & out $/ 13$ & $\operatorname{dez} / 13$ & $\mathrm{jan} / 14$ & fev $/ 14$ & $\operatorname{mar} / 14$ & $\mathrm{abr} / 14$ & mai/14 & jul/14 & rain & drought & \\
\hline $\begin{array}{l}\text { Total of } R \text {. (B.) microplus (between } 4.5-8.0 \mathrm{~mm} \text { ) } \\
\text { quantified on animals of both groups/repeat }\end{array}$ & 790 & 1682 & 719 & 897 & 818 & 505 & 279 & 753 & 4906 & 1537 & \\
\hline $\begin{array}{l}\text { Total of } R \text {. (B.) microplus (between } 4.5-8.0 \mathrm{~mm} \text { ) } \\
\text { quantified on animals with tick counts } \geq 20\end{array}$ & 702 & 1608 & 634 & 836 & 711 & 469 & 268 & 656 & 4491 & 1393 & - \\
\hline $\begin{array}{l}\text { Total of } R \text {. (B.) microplus (between } 4.5-8.0 \mathrm{~mm} \text { ) } \\
\text { quantified on animals with tick counts }<20\end{array}$ & 88 & 74 & 85 & 61 & 107 & 36 & 11 & 97 & 415 & 144 & - \\
\hline $\begin{array}{l}\text { Percentage of tick population, quantified on } \\
\text { animals, that would be treated with } \\
\text { chemicals formulations with the adoption of } \\
\text { partial selective treatment }\end{array}$ & 88.9 & 95.6 & 88.2 & 93.2 & 86.9 & 92.9 & 96.1 & 87.1 & 91.5 & 90.6 & 91.3 \\
\hline $\begin{array}{l}\text { Percentage of tick population, quantified on } \\
\text { animals, that would be not treated with the } \\
\text { adoption of partial selective treatmen }\end{array}$ & 11.1 & 4.4 & 11.8 & 6.8 & 13.1 & 7.1 & 3.9 & 12.9 & 8.5 & 9.4 & 8.7 \\
\hline
\end{tabular}

a In acordance with the metodology adoted in this study (all animais of each group/repeat was treated when the mean count of ticks was $\geq 30$ ).

b In acordance with the metodology described by Paim et al. (2011) and Molento et al. (2013). 
however, the results obtained in the present study suggest that partial selective treatments would most likely not be able to slow the development of resistance of this $R$. (B.) microplus population to the chemical compounds used in this study.

\section{Conflicts of interest}

There were no conflicts of interest that may have biased the work reported in this paper.

\section{References}

Corrêa, R.R., Lopes, W.D.Z., Teixeira, W.F.P., Cruz, B.C., Gomes, L.V.C., Felippelli, G., Maciel, W.G., favero, F., Buzzulini, C., Bichuette, M.A., Soares, V.E., Costa, A.J., 2015. A comparison of three different methodologies for evaluating Rhipicephalus (Boophilus) microplus susceptibility to topical spray compounds. Vet. Parasitol. 207, 115-124

Cruz, B.C., Lopes, W.D.Z., Maciel, W.G., Felippelli, G., Favero, F.C., Teixeira, W.F.P., Carvalho, R.S., Ruivo, M.A., Colli, M.H.A., Sakamoto, C.A.M., Costa, A.J., Oliveira, G.P., 2015. Susceptibility of Rhipicephalus (Boophilus) microplus to ivermectin $(200,500$ and $630 \mu \mathrm{g} / \mathrm{kg})$ in field studies in Brazil. Vet. Parasitol. 207, 309-317.

Evans, D.E., 1978. Boophilus Microplus Ecological Studies and a Tick Faune Synopsis Related to the Developing Cattle Industry in the Latin American and Caribbean Region. Thesis (PhD). Council National Academic Awards, London (283 pp.).

Filho, D.B.F., Junior, J.A.S., 2009. Desvendando os mistérios do coeficiente de correlação de pearson (r). Rev. Política Hoje 18, 115-146.
Gomes, L.V.C., Lopes, W.D.Z., Cruz, B.C., Teixeira, W.F.P., Felippelli, G., Maciel, W.G., Bichuette, M.A., Ruivo, M.A., Colli, M.H.A., Carvalho, R.S., Martinez, A.C., Soares, V.E., Costa, A.J., 2015. Acaricidal effects of fluazuron $(2.5 \mathrm{mg} / \mathrm{kg})$ and a combination of fluazuron $(1.6 \mathrm{mg} / \mathrm{kg})+$ ivermectin $(0.63 \mathrm{mg} / \mathrm{kg})$ administered at different routes, against Rhipicephalus (Boophilus) microplus parasitizing cattle. Exp. Parasitol. 153, 22-28.

Lopes, W.D.Z., Teixeira, W.F.P., Matos, L.V.S., Felippelli, G., Cruz, B.C., Maciel, W.G. Buzzulini, C., Fávero, F.C., Soares, V.E., Oliveira, G.P., Costa, A.J., 2013. Effects of macrocyclic lactones on the reproductive parameters of engorged Rhipicephalus (Boophilus) microplus females detached from experimentally infested cattle. Exp. Parasitol. 135, 72-78.

Lopes, W.D.Z., Cruz, B.C., Teixeira, W.F.P., Felippelli, G., Maciel, W.G., Buzulini, C., Gomes, L.V.C., Favero, F., Soares, V.E., Bichuette, M.A., Oliveira, G.P., Costa, A.J., 2014. Efficacy of fipronil (1.0 mg/kg) against Rhipicephalus (Boophilus) microplus strains resistant to ivermectin (0.63 mg/kg). Prev. Vet. Med. 115, 88-93.

Molento, M.B., Fortes, F.S., Buzatti, A., Kloster, F.S., Sprenger, L.K., Coimbra, E., Soares, L.D., 2013. Partial selective treatment of Rhipicephalus microplus and breed resistance variation in beef cows in Rio Grande do Sul Brazil. Vet. Parasitol. 192, 234-239.

Nava, S., Mangola, A.J., Canaveri, J.T., Guglielmone, A.A., 2015. Strategic applications of long-acting acaricides against Rhipicephalus (Boophilus) microplus in northwestern Argentina, with an analysis of tick distribution among cattle. Vet. Parasitol. 208, 225-230.

Paim, F., Souza, A.P., Bellato, V., Sartor, A.A., 2011. Selective control of Rhipicephalus (Boophilus) microplus in fipronil treated cattle raised on natural pastures in Lages State of Santa Catarina, Brazil. Rev. Bras. Parasitol. Vet. 20, 13-16.

Wharton, R.H., Utech, K.B.W., 1970. Relation between engorgement and dropping of Boophilus microplus to assessment of tick number in cattle. Aust. Entomol. Soc. 9, 171-182. 